\title{
Use of an Autologous Lamellar Scleral Graft to Repair a Scleral Melt After Mitomycin Application
}

Nihat Polat

To view enhanced content go to www.ophthalmology-open.com

Received: September 20, 2014 / Published online: November 22, 2014

(c) The Author(s) 2014. This article is published with open access at Springerlink.com

\section{ABSTRACT}

Mitomycin (MMC) has been associated with a variety of complications, including corneoscleral melt. We report the successful repair of a scleral melt with a partial thickness autologous scleral graft of the scleral melting. A 55-year-old male patient underwent pterygium resection surgery and intraoperative MMC application. The patient developed a deep melting area that almost reached the choroid layer at the nasal sclera. We repaired scleral defect with a partial thickness autologous scleral graft. Closure of an MMC-associated scleral melting area with an autologous partial thickness scleral graft is an effective and easy-touse method.

Keywords: Autologous; Mitomycin;

Scleral graft; Scleral melting

Electronic supplementary material The online version of this article (doi:10.1007/s40123-014-0026-7) contains supplementary material, which is available to authorized users.

\section{N. Polat $(\square)$}

Department of Ophthalmology, Medical Faculty, Inonu University, 44280 Malatya, Turkey

e-mail: drnihatpolat@gmail.com

\section{INTRODUCTION}

Mitomycin (MMC) application has been shown to be effective in preventing recurrence in pterygium surgery $[1,2]$. MMC is an alkylating agent that reduces pterygium recurrence by inhibiting fibrovascular growth and has been demonstrated to be a useful adjunct for this surgery [3]. Unfortunately, MMC has also been to be associated with a variety of complications, including corneoscleral melt [3]. The scleral defect must be covered with donor tissue to prevent subsequent infection or perforation in such cases. The materials used for this complication include preserved sclera, cornea, pericardium, dura or amniotic membrane [4]. We report the successful repair with a partial thickness autologous scleral graft of the scleral melting that developed in a patient who underwent pterygium surgery with MMC.

\section{CASE}

A 55-year-old male patient underwent pterygium resection surgery and intraoperative MMC application at an external center for the pterygium in his right eye, 6 months ago. The patient developed a deep melting area that 
almost reached the choroid underlying the nasal sclera during follow-up and was referred to our clinic. The examination revealed full visual acuity bilaterally with normal biomicroscopy and retinal findings in the left eye. A scleral melt area with a diameter of $0.5-0.75 \mathrm{~cm}$ and extending almost to the choroid except for a thin membrane was present approximately $1 \mathrm{~cm}$ away from the limbus at the nasal section of the right eye. Normal vascularization was severely decreased in the defect starting from the limbus (Fig. 1). It was decided to close the defect as the area was open to trauma.

The conjunctiva in the defect region of the right eye was dissected under retrobulbar anesthesia. The edges of the scleral defect were trimmed with a crescent knife to ensure donor tissue as the graft site would adhere easily. In the same eye, the conjunctiva and Tenon's capsule in the upper temporal region were then dissected. A partial thickness scleral graft about $0.75-1.00 \mathrm{~cm}$ and suitable for the defect region in size was then removed from the upper temporal region with a $45^{\circ}$ surgical knife. Dissection was performed with utmost care in order not to create scleromalacia in the area. The Tenon's capsule and conjunctiva in the region where the graft was taken were primarily closed

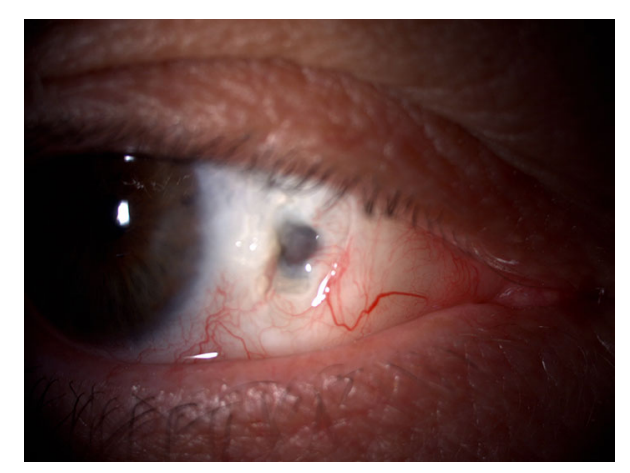

Fig. 1 Pre-operative appearance of the sclera melt in the right eye after pterygium resection surgery and intraoperative mitomycin with 8-0 vicryl. The removed graft was placed in the appropriate position so as to close the defect region and sutured with 8-0 vicryl. The Tenon's capsule and conjunctival tissue at the site of the sclera defect were freed with blunt dissection and sutured with 8-0 vicryl so as to close the entire defect region. There were no complications and surgery was ended with a subconjunctival gentamicin and dexamethasone injection. Postoperatively moxifloxacin, one drop, five times a day and florometolon, one drop, four times a day were started and the patient was monitored. The patient had no symptoms except for minimal stinging at the postoperative first week. On examination, the conjunctiva was hyperemic, the graft intact, the sutures unharmed, visual acuity full, and the intraocular pressure and retinal findings normal. No complication was observed in the postoperative first month. The visual acuity was full, and the intraocular pressure and retinal findings were normal. The patient had no symptoms and the drops were stopped. In the third postoperative month it was seen that the defect had completely healed and was well covered by a vascular conjunctiva. The region providing the graft had also healed without any complication. The visual acuity was full, and the intraocular pressure and retinal findings were normal (Fig. 2).

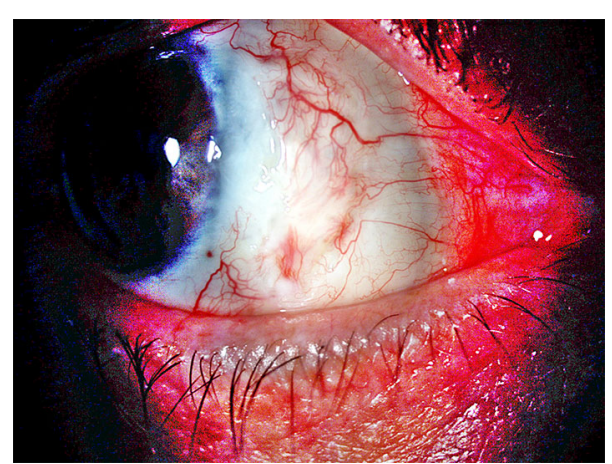

Fig. 2 Post-operative appearance of the autologous lamellar scleral graft bed at 3 months 
Informed consent was obtained from the patient for being included in the study.

\section{DISCUSSION}

MMC is used in many areas such as glaucoma and pterygium surgery. MMC can cause serious problems in tissues such as the cornea and sclera if used for a longer duration than usual or not sufficiently irrigated and removed afterwards [3]. Our patient was operated on in an external center so we did not know which MMC regimen had been employed. Severe damage occurred in the nasal region, affecting the conjunctiva, Tenon's capsule and sclera of our case with sclera melting almost to the choroid. In such cases, the choroid can be ruptured by minimal trauma to the eye, leading to vitreous loss and the risk of infection, including endophthalmitis. Amniotic membrane, fascia lata, pericardium, dura mater, and corneal or scleral grafts can be used to repair the defect $[4,5]$. A scleral graft has been used to treat perforated corneal ulcer, scleral melting, or scleromalacia as it is strong, flexible, easy to handle, and can be placed on host sclera [6-8]. A scleral graft can also be used in the cosmetic closure of an Ota nevus [9]. The scleral graft can be obtained from another donor or from the patient's same or the other eye [8]. We preferred partial thickness autologous sclera because a relatively small graft was required, removal of sclera from the temporal site was straightforward and there was no risk of rejection using this approach. The upper temporal region was preferred as a site distant from the earlier MMC exposure, where scleral removal is easy. However, excessively deep incisions during removal of the graft may lead to choroidal and retinal damage or cause later staphyloma formation. Scleral perforation under the suture is another significant complication that may occur. The repair did not cause any preoperative or postoperative complications in our case.

In conclusion, closure of an MMC-associated scleral melting area with an autologous partial thickness scleral graft is an effective and easy-touse method.

\section{ACKNOWLEDGMENTS}

No funding or sponsorship was received for this study or publication of this article. The author meets the ICMJE criteria for authorship for this manuscript, takes responsibility for the integrity of the work as a whole, and has given final approval for the version to be published.

Conflict of interest. Nihat Polat declares no conflict of interest.

Compliance with ethics guidelines. Informed consent was obtained from all patients for being included in the study.

Open Access. This article is distributed under the terms of the Creative Commons Attribution Noncommercial License which permits any noncommercial use, distribution, and reproduction in any medium, provided the original author(s) and the source are credited.

\section{REFERENCES}

1. Segev F, Jaeger-Roshu S, Gefen-Carmi N, Assia EI. Combined mitomycin $\mathrm{C}$ application and free flap conjunctival autograft in pterygium surgery. Cornea. 2003;22(7):598-603.

2. Hirst LW. Mitomycin C in the treatment of pterygium. Clin Exp Ophthalmol. 2006;34(3):197-8. 
3. Rubinfeld RS, Pfister RR, Stein RM, et al. Serious complications of topical mitomycin-C after pterygium surgery. Ophthalmology. 1992;99(11): 1647-54.

4. Prydal JI. Use of an autologous lamellar scleral graft to repair corneal perforation. Br J Ophthalmol. 2006; 90:924-5.

5. Ti SE, Tan DTH. Tectonic corneal lamellar grafting for severe scleral melting after pterygium surgery. Ophthalmology. 2003;110:1126-36.

6. Levartovsky S, Springer A, Leiba H, Marcovich AL, Pollack A. Homologous scleral graft for corneal perforation in a child. Cornea. 2008;27:230-1.
7. Oh JH, Kim JC. Repair of scleromalacia using preserved scleral graft with amniotic membrane transplantation. Cornea. 2003;22:288-93.

8. Sangwan VS, Jain V, Gupta P. Structural and functional outcome of scleral patch graft. Eye. 2007; 21:930-5.

9. Cho BJ, Kwon JW, Han YK, Kim JH, Wee WR, Lee JH. Cosmetic improvement of nevus of Ota by scleral allograft overlay. Can J Ophthalmol. 2011;46(5): 428-30. 